\title{
Optimal Reduced Order Model of Single- Shaft Heavy Duty Gas Turbine Power Plants
}

\author{
M. Ramasubramanian. \\ Chemical Engineering Department \\ Coimbatore Institute of Technology Coimbatore, India
}

\author{
M. Thirumarimurugan. \\ Chemical Engineering Department \\ Coimbatore Institute of Technology Coimbatore, India
}

\author{
P. Ananthi. EEE Department \\ K.R.C.E \\ Trichy, India
}

\begin{abstract}
Design of controller and analyzing the response of higher order system in real time environment would be very complex and expensive. Therefore, an attempt has been made in this paper to obtain the reduced order model of single-shaft Heavy duty gas turbine plants ranging from 18.2 to $106.7 \mathrm{MW}$ by using various model order reduction techniques. The step response of Heavy duty gas turbine model using the reduced order models are compared with that of the original MATLAB/ Simulink model. Various time domain specifications and performance index criteria have been considered for analyzing the responses. The simulation results show that the response obtained by Routh approximation-Pade approximation technique based reduced order model mimics the original, higher order Heavy Duty gas turbine response. It is also proposed in this paper to improve the response by optimizing the co-efficients of reduced order model using Particle Swarm Optimization technique. On comparing the simulation results, Particle Swarm Optimization technique based reduced order model yield better transient and steady state response as close to original higher order system and hence it is identified as an optimal reduced order model for all Heavy Duty gas turbine plants in grid connected operation.
\end{abstract}

Keywords:- MATLAB, Modelling, Particle Swarm Optimization, System Performance, Turbines.

\section{INTRODUCTION}

Climate change, increasing $\mathrm{CO} 2$ emission and greenhouse gas emissions mostly causes environmental degradation and hence the global warming. These shortcomings can be overcome by using renewable energy sources such as solar, wind, biomass etc for electrical power generation. The bio- gas fuel has special characteristics such as high and variable moisture content, very low sulphur content, low ash content, low density and fibrous structure. Therefore, the biomass is considered as a source for power generation using gas turbine [2].
Heavy duty gas turbines are installed for power generation worldwide, due to its higher thermal efficiency, lower greenhouse emissions and fast starting capability etc [3]. Speedtronic and Woodward governor are used as the primary controllers for speed control of HDGT plants [4][6]. For simple cycle operation, Rowen has developed a simplified mathematical model for all HDGT plants that can be used for dynamic power system studies [4]. The dynamic behavior of $150 \mathrm{MW}$ HDGT was analyzed based on field data and its model parameters are estimated by available operational and performance data [7], [8]. The literature also reveals that the droop governor yield better performance [9], [10]. Many researchers have also modeled the HDGT plant and analyzed the response in combined cycle operation [11][14]. The sample survey of 84 biomass gasifier plants conducted in Tamil Nadu, India, also reveals that the response of the plants are influenced by many factors such as lack of monitoring and control [15], [16]. In order to improve the dynamic and steady state response, an attempt had been made to develop Proportional-Integral-Derivative (PID) controller and soft computing controllers for the HDGT plants [17]-[22].

Panda $\mathrm{S}$ et al. revealed that the design, analysis and controller synthesis for higher order system in real time applications are tedious and expensive [23]. In order to overcome this complexity, development of reduced order model (ROM) of the higher order system is essential. Therefore, the authors have attempted to identify the Linearized transfer function model (LTFM) of HDGT plants and compared the responses with original system [24]. This forms as the base for the development of ROM of HDGT plant.

In this paper, it is proposed to identify the reduced order model of all HDGT plants using various model order reduction techniques [25]-[33]. The step response of ROM of all HDGT plants has been compared with that of the original MATLAB/Simulink model (MSM) to rescue whether it retains the original characteristics. Further, it is proposed to improve the response of ROM by using the most popular Particle Swarm Optimization (PSO) Technique. The algorithmic steps for model order reduction and the simulation results of the ROM are furnished in this paper. 


\section{MODELING OF GAS TURBINE}

The transfer function model of single-shaft HDGT which was developed by Rowen in the year 1983 includes various limiters, fuel system, compressor and turbine system [4]. Modeling of various controllers namely speed governor, acceleration and temperature controllers along with an algebraic equation depicting the static characteristics of the turbine and time delays are presented in [22], [24]. Low value select LVS) block as shown in Figure 1, selects the controller whose output is minimum and take the respective control action.

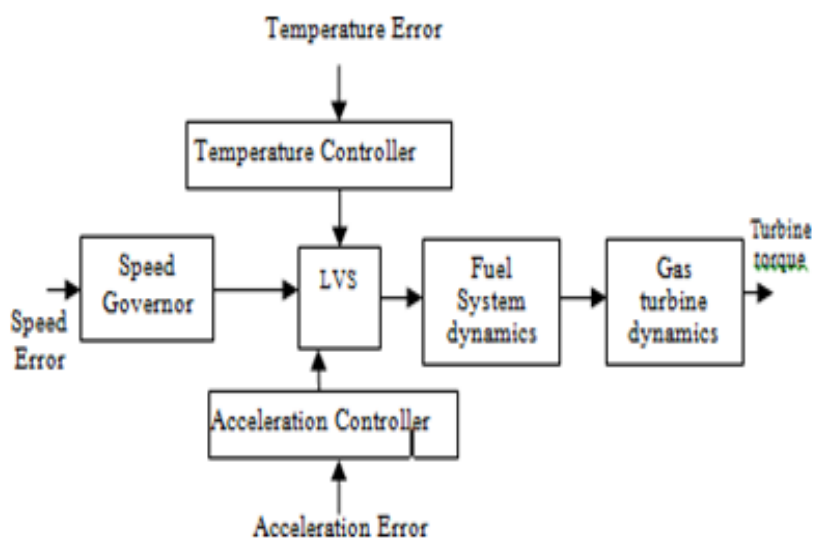

Fig 1:- Block diagram of Single-shaft HDGT

The transfer function of valve positioner and fuel system actuator is given in Equation (1) and (2). The fractional amount rated fuel about $23 \%$ is required to support self- sustaining under no-load conditions.

$$
\begin{aligned}
& \frac{V p(s)}{W d(s)}=\frac{a}{b s+c} \\
& \frac{W f(s)}{V p(s)}=\frac{1}{T s+1}
\end{aligned}
$$

The gas turbine dynamics includes the combustor delay and torque functions denoted by F1 and F2 as shown in Equation (3) and (4).

$$
\begin{aligned}
& \mathrm{F} 1=\mathrm{TX}=\mathrm{TR}-390(1-\mathrm{Wf} 2)-306(1-\mathrm{N}) \\
& \mathrm{F} 2=1.3(\mathrm{Wf} 2-0.23)+0.5(1-\mathrm{N})
\end{aligned}
$$

The acceleration controller is useful only during startup time and it will be inactive, when the frequency deviation is not greater than $\pm 1 \%$. The temperature controller takes the control action only when the exhaust temperature exceeds the limit and hence the need for temperature controller is diminished. Based on these behaviors, the simplified model with predominant speed controller is identified. The transfer function of speed governor showing the relationship between speed deviation (e) and controller output (C) is shown in Equation (5) and the simplified model is shown in Figure 2.

$$
\frac{\mathrm{C}(\mathrm{s})}{\mathrm{e}(\mathrm{s})}=\frac{\mathrm{W}(\mathrm{Xs}+1)}{\mathrm{Y}+\mathrm{Z}}
$$

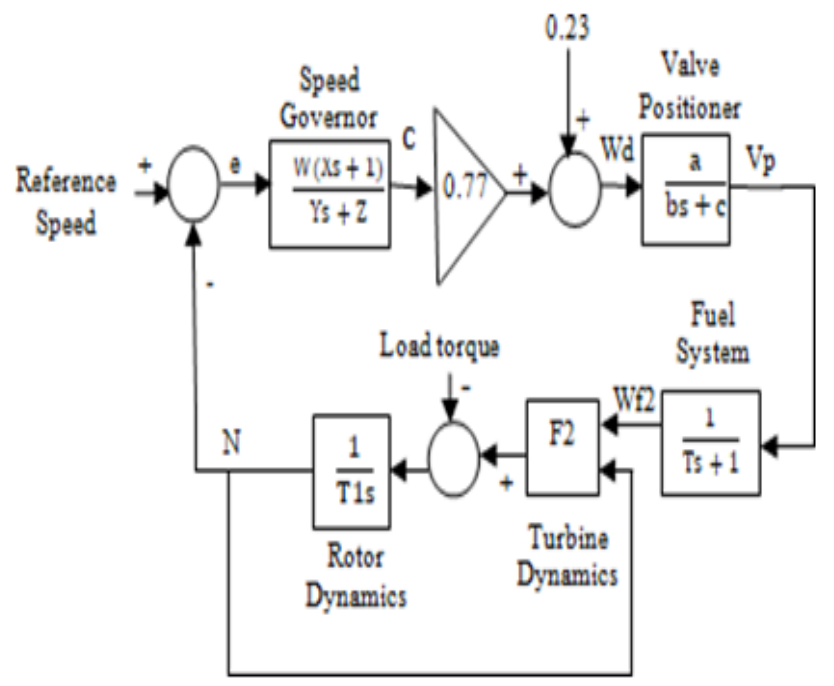

Fig 2:- Simplified transfer function model of HDGT plant

Based on the simulation response, it was found that the secondary controllers are required to improve the steady state response of HDGT plant [9]. Controller development for the higher order HDGT plant and analyzing its response in real time would be difficult and expensive. Therefore, it is necessary to reduce the order of the HDGT plant without affecting its original behavior. In this paper, it is proposed to obtain the ROM and identify the optimal ROM for all HDGT plants.

\section{REDUCED ORDER MODEL OF HDGT}

The mathematical modeling of real time system has been obtained from theoretical considerations and it may lead to higher order transfer function. Controller design and analysis of such a higher order system is very complicated and expensive [23]. Therefore, it is required to identify the reduced order model which retains the important dynamic behavior of the original system. The ROM reduces the hardware complexity and computational complexity.

In many practical applications, the higher order system is fairly complex which often makes it difficult to understand the original behavior of the system. Therefore, it is necessary to find the reduced order model by approximating the original characteristics of the system using model order reduction techniques.

In this paper, the model order reduction techniques such as Routh approximation, Pade approximation, Modified Pole Clustering, Clustering technique, Mihailov Criterion and Eigen Permutation algorithm are used to obtain the ROM of all HDGT plants. The algorithmic steps to be followed for obtaining ROM using these techniques are briefed below. 
Eigen Permutation algorithm (EPA) is a stable criterion based reduction technique. This algorithm is simple, computer oriented and efficient [26].

Step 1: Eigen permutation algorithm is used to reduce the denominator polynomial and its algorithm is given in Figure

3. Consider, the higher order transfer function

$$
\mathrm{G}(\mathrm{s})=\frac{\mathrm{P}(\mathrm{S})}{\mathrm{Q}(\mathrm{S})}=\frac{d_{0}+d_{1} s+d_{2} s^{2}+\cdots d_{n-1} s^{n-1}}{c_{0}+c_{1} s+c_{2} s^{2}+\cdots c_{n} s^{n}} \text { of } \mathrm{n}^{\text {th }} \text { order. }
$$

Consider, the reduced order transfer function,

$$
\mathrm{G}_{\mathrm{r}}(\mathrm{s})=\frac{\mathrm{P}_{\mathrm{r}}(\mathrm{S})}{\mathrm{Q}_{\mathrm{r}}(\mathrm{S})}=\frac{t_{0}+t_{1} s+t_{2} s^{2}+\cdots t_{r-1} s^{r-1}}{u_{0}+u_{1} s+u_{2} s^{2}+\cdots u_{r} s^{r}}
$$

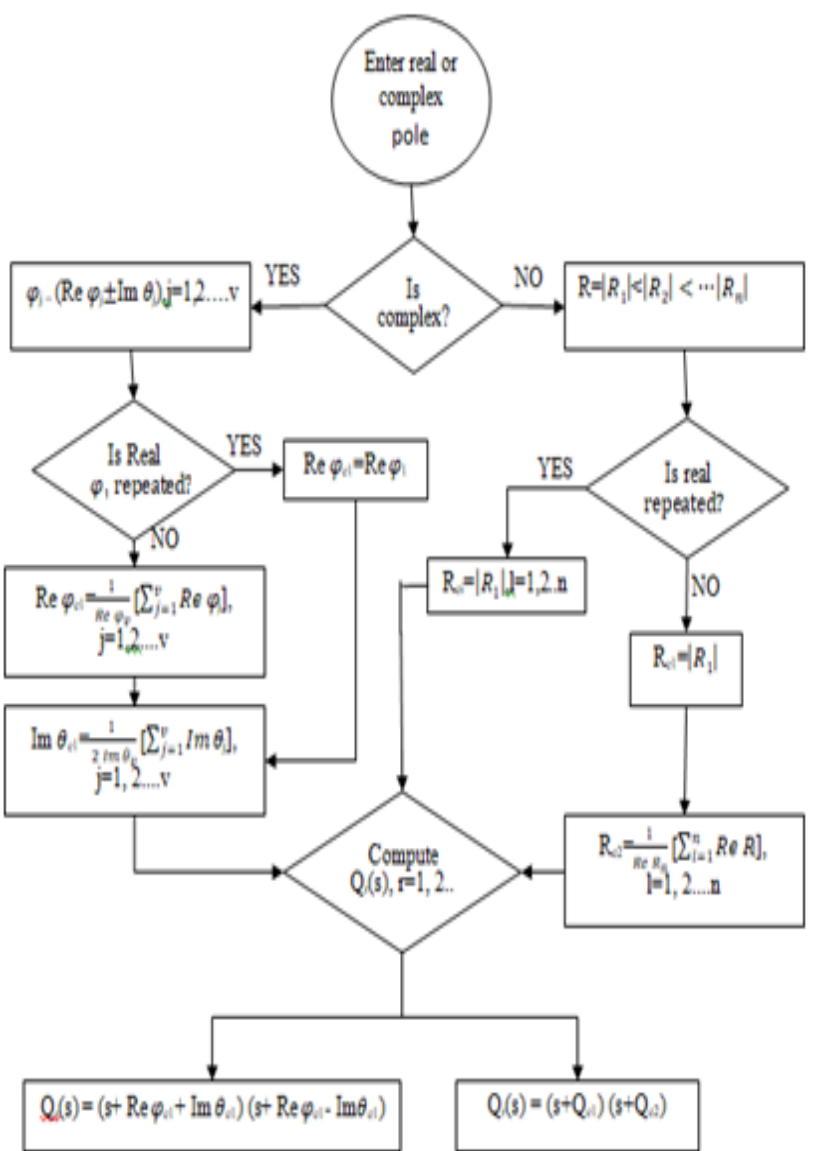

Fig 3:- Flow chart for Eigen Permutationalgorithm

Step 2: The numerator polynomial of the ROM, $\operatorname{Pr}(\mathrm{s})$ is obtained using Pade approximation technique

Routh approximation (RA) is stability criterion based reduction technique. In this technique, all the sequence of approximants is converging monotonically to the original system and if the original system is stable, the approximants will also be stable [27]. In this paper, RA is used to reduce the denominator polynomial by the following procedure.
Step 1: Apply reciprocal transform of denominator polynomial, Q(s).

Step 2: Construct alpha table from the co-efficients of reciprocal transform of $\mathrm{Q}(\mathrm{s})$. The co-efficients of reduced order denominator, $\mathrm{Qr}(\mathrm{s})$ are calculated using alpha table shown as Table I.

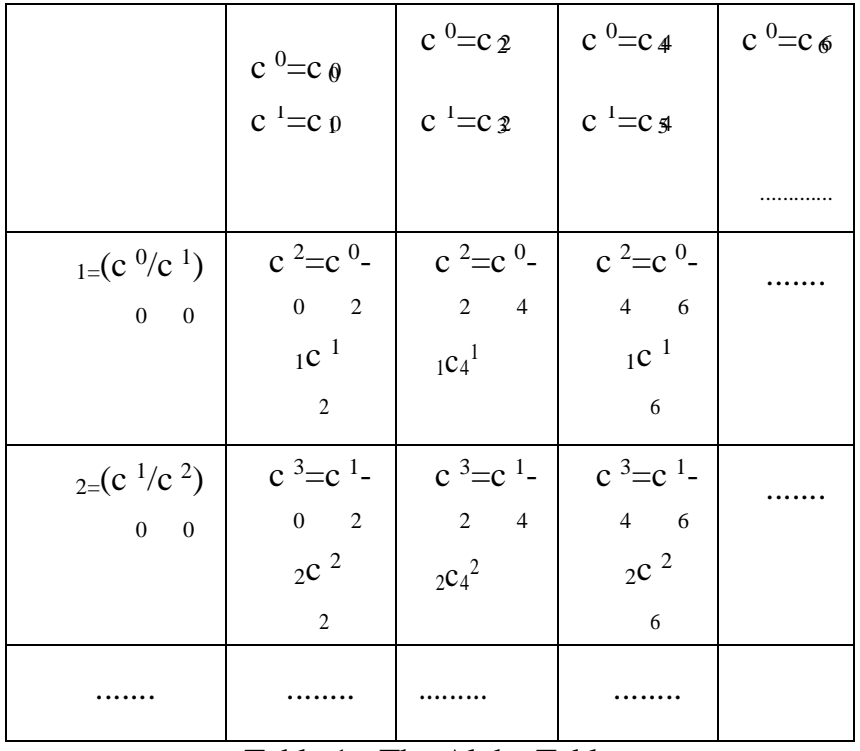

Table 1:- The Alpha Table

Step 3: Find the reduced order denominator polynomial using recursive equation as expressed in Equation (6). Based on the required order of reduced order model, the respective Qr(s) can be obtained.

$$
\begin{aligned}
& \mathrm{Q}_{1}(\mathrm{~s})=1+\alpha_{1} \mathrm{~s} \\
& \mathrm{Q}_{2}(\mathrm{~s})=1+\alpha_{1} \mathrm{~s}+\alpha_{1} \alpha_{2} \mathrm{~s}^{2} \\
& \mathrm{Q}_{\mathrm{r}}(\mathrm{s})=\alpha_{\mathrm{r}} \mathrm{s} \mathrm{Q}_{\mathrm{r}-1}(\mathrm{~s})+\mathrm{Q}_{\mathrm{r}-2}(\mathrm{~s}), \mathrm{r}=1,2 \ldots \\
& \text { and } \\
& \mathrm{Q}_{-1}(\mathrm{~s})=\mathrm{Q}_{0}(\mathrm{~s})=1
\end{aligned}
$$

Step 4: Find reduced order denominator polynomial by applying reciprocal transform of above equation.

Step 5: The numerator polynomial of the ROM, $\operatorname{Pr}(\mathrm{s})$ is obtained using Pade approximation technique.

Clustering technique (CT) is used to reduce the denominator polynomial of the original higher order system [28]. The criterion for pole clustering is based on the relative distance between the higher order poles and the order of the ROM. The pole clustering of the original higher order system is generated by the following procedure.

1. Real and complex poles should be made as separate clusters.

2. The poles present in a cluster should be unique i.e. either from left half of s-plane or right half of s- plane.

3. Poles on the imaginary axis and at the origin are retained in the ROM. 
Step 1: The cluster centre of the ' $n$ ' real poles in lth cluster can be obtained by using the Equation (7),

$$
\mathrm{R}_{\mathrm{c}}=\left[\left(\sum_{l=1}^{n}\left(\frac{1}{R_{l}}\right)\right) / n\right]^{-1}
$$

Step 2: The cluster centre of the ' $\mathrm{v}$ ' pair of complex conjugate poles in jth cluster can be obtained in the form of $\mathrm{Cc} \pm \mathrm{jDc}$ by using the Expression (8),

$$
\mathrm{C}_{\mathrm{c}}=\left[\left(\sum_{j=1}^{v}\left(\frac{1}{\varphi_{j}}\right)\right) / v\right]^{-1} \& \mathrm{D}_{\mathrm{c}}=\left[\left(\sum_{j=1}^{v}\left(\frac{1}{\theta_{j}}\right)\right) / v\right]^{-1}
$$

The following rules are used to synthesis the rth order denominator polynomial, based on the nature of the pole cluster centres.

Rule 1: The reduced order denominator as shown in Equation (9) can be used, if all the cluster centres are real.

$\operatorname{Qr}(s)=\left(s-R_{c} 1\right)\left(s-R_{c}\right) \ldots \ldots . .\left(s-R_{c r}\right)$

Where Rc1, Rc2... Rcr = 1st, 2nd ....rth real cluster centre.

Rule 2: The reduced order denominator as shown in Equation (10) can be used, if all the cluster centres are complex conjugate.

$\operatorname{Qr}(\mathrm{s})=\left(\mathrm{s}-\left(\mathrm{C}_{\mathrm{c} 1} \pm \mathrm{j} \mathrm{Dc} 1\right)\right) \quad\left(\mathrm{s}-\left(\mathrm{C}_{\mathrm{c}} 2 \pm \mathrm{jD} \mathrm{D} 2\right)\right) \quad\left(\mathrm{s}-\quad\left(\mathrm{C}_{\mathrm{c}} \pm \mathrm{j} \mathrm{D} \mathrm{cr}\right)\right)$ (10)

Where $\mathrm{Cc} 1 \pm \mathrm{jDc} 1, \mathrm{Cc} 2 \pm \mathrm{jDc} 2 \ldots . . \mathrm{Ccr} \pm \mathrm{jDcr}=1 \mathrm{st}, \quad 2 \mathrm{nd}$ ....rth complex conjugate cluster centre.

Rule 3: The reduced order denominator as shown in Equation (11) can be used, if some cluster centre has the combination of both.
$\operatorname{Qr}(\mathrm{s})=\left(\mathrm{s}-\mathrm{R}_{\mathrm{c} 1}\right)\left(\mathrm{s}-\mathrm{R}_{\mathrm{c}} 2\right)$
$(\mathrm{s}-\mathrm{R} \mathrm{cr})(\mathrm{s}-(\mathrm{C} \mathrm{c} 1 \pm \mathrm{jD} \mathrm{c} 1)) \ldots(\mathrm{s}-$
$(\mathrm{C} c r \pm j \mathrm{j} c r))$

Step 3: The numerator polynomial of the ROM, $\operatorname{Pr}(\mathrm{s})$ is obtained using Pade approximation technique.

The reduced order denominator polynomial obtained by CT may sometime become unstable, though the original higher order system is stable.

An effective pole cluster centres are generated to overcome the drawback of CT by Modified Pole Clustering (MPC) technique [29]. This technique is used to reduce the denominator polynomial by the procedure as given below. The following steps are used to find the modified cluster centre.

Step 1: The ' $\mathrm{n}$ ' real poles are contained in lth cluster, where $\left|R_{1}\right|<\left|R_{2}\right|<\ldots .\left|R_{n}\right|$
Step 2: Consider ' $m$ ' as the reduced order count. Set $m=1$ and the pole cluster centre is obtained by using the Equation (12),

$$
\mathrm{C}_{\mathrm{m}}=\left[\left(\sum_{l=1}^{n}\left(\frac{1}{R_{l}}\right)\right) / n\right]^{-1}
$$

Step 3: Increase the count by one i.e. $m=m+1$

Step 4: The modified pole cluster centre is obtained by using the Equation (13),

$$
\mathrm{C}_{\mathrm{m}}=\left[\left(\frac{-1}{\left|\mathrm{R}_{1}\right|}+\frac{-1}{\left|\mathrm{C}_{\mathrm{m}-1}\right|}\right) / 2\right]^{-1}
$$

Step 5: Check whether the desired order of ROM is reached i.e. $r=m$. If yes, then go to step 6. Otherwise go to step 3 . Step 6: Then the modified cluster center of $\mathrm{r}^{\text {th }}$ cluster can be obtained by using the Equation (14),

$\mathrm{R} c r=\mathrm{Cm}$

The same procedure can be applied for complex conjugate poles and find the modified cluster centre.

Mihailov Criterion (MC) technique is a stability based reduction technique. It is used to reduce the denominator polynomial by the procedure mentioned below [30]. Consider the denominator of the Original higher order system as Q(s).

Step 1: Substituting $s=j \omega$ in denominator polynomial and separating into real and imaginary parts in the form as shown in Equation (15).

$$
\mathrm{Q}(\mathrm{j} \omega)=\gamma(\omega)+j \tau(\omega)
$$

Step 2: Setting real and imaginary parts as zero and then find the intersecting frequencies namely $\omega 1, \omega 2$

Step 3: Then reduced order denominator polynomial is obtained as shown in Equation (16),

$$
O_{i}(i \omega)=\rho(\partial+\mathrm{i} \quad \delta(\omega)
$$

Where,

Real part of reduced order denominator polynomial is obtained as shown in Equation (17),

$$
\rho(\omega)=\sigma_{1}\left(\omega^{2}-\omega_{1}^{2}\right)\left(\omega^{2}-\omega_{3}^{2}\right)\left(\omega^{2}-\omega_{5}^{2}\right)
$$

Imaginary part of reduced order denominator polynomial is obtained as shown in Equation (18), 


$$
\delta(\omega)=\sigma_{2}\left(\omega^{2}-\omega_{2}^{2}\right)\left(\omega^{2}-\omega_{4}^{2}\right)\left(\omega^{2}-\omega_{\sigma}^{2}\right)
$$

Step 4: From the Equation (17) and (18), $\sigma 1$ and $\sigma 2$ are computed from $\rho(0)=\gamma_{(0)}$ and $\rho(\omega 1)=\gamma_{(\omega 1)}$ respectively.

Step 5: Then the value of 1 and 2 are $\sigma_{\text {substituted back in }}$ Equation (17) and (18) and the reduced order denominator polynomial is obtained.

Step 6: Find the rth order denominator polynomial Qr(s), by substituting $\mathrm{j} \omega=\mathrm{s}$ in Equation (16).

Pade approximation (PA) technique has many advantages such as computational simplicity, fitting of the initial time moments and matching with the steady state values etc. This technique is mostly used along with other methods to obtain the ROM [31]. The procedure for reducing the numerator polynomial of original system is briefed below

Step 1: The original higher order transfer function can be expanded in power series about $\mathrm{s}=0$ and expressed as in Equation (19),

$$
\mathrm{G}(\mathrm{s})=\frac{\sum_{i-0}^{n-1} d_{i} s^{i}}{\sum_{i=0}^{n} c_{i} s^{i}}=\underset{0}{\mathrm{e}}+\underset{1}{\mathrm{e}} \mathrm{s}+\mathrm{e}_{2} \mathrm{~s}^{2}
$$

The coefficients of the power series expansion are expressed in Equation (20),

$$
\begin{aligned}
& \mathrm{e}_{0}-\frac{d_{0}}{c_{0}} \\
& \mathrm{e}_{1}-\frac{1}{c_{0}}\left[d_{i}-\sum_{j=1}^{i} c_{j} e_{i-j}\right], \mathrm{i}>0 \text { and so on. }
\end{aligned}
$$

Step 2: The reduced order numerator coefficients by this technique are obtained as shown in Equation (21).

$\mathrm{t} 0=\mathrm{u} 0 \mathrm{e} 0$

$\mathrm{t} 1=\mathrm{u} 0 \mathrm{e} 1+\mathrm{u} 1 \mathrm{e} 0$

$\operatorname{tr}-1=\mathrm{u} 0 \mathrm{er}-1+\mathrm{u} 1 \mathrm{er}-2+\ldots . .+\mathrm{ur}-1 \mathrm{e} 0$

The coefficients of power series expansion ( 0 , e1...er-1) and the reduced order denominator co-efficients (u0, u1...ur) that obtained using any of the above methods are used for this purpose.

Step 3: The reduced order model numerator can be expressed in Equation (22),

$\operatorname{Pr}(\mathrm{s})=\mathrm{t} 0+\mathrm{t} 1 \mathrm{~s}+\ldots \ldots+\mathrm{tr}-1 \mathrm{~s}^{\mathrm{r}-1}$
For obtaining the ROM of the HDGT plants, the PA technique is used to obtain the numerator polynomial and the denominator polynomial is obtained by EPA, RA, CT, MPC and MC techniques. The step response of all the ROM pertaining to each and every HDGT plant is obtained and the optimal ROM is obtained as explained in Section IV.

\section{OPTIMAL REDUCED ORDERMODEL}

In recent years, the evolutionary techniques such as Ant Bee Colony algorithm, Tabu search, simulated annealing, Genetic algorithm (GA) and PSO etc are used for optimization in many engineering problems. Among these evolutionary techniques GA and PSO are the most promising algorithm for handling the optimization problem. Since, PSO algorithm is easy to implement and there are only few parameters to adjust during optimization. It is used in this paper to optimize the co-efficients of the ROM.

PSO is a population based optimization algorithm that has been proposed by Dr. Eberhart and Dr. kennedy in 1995 [32]. In this paper, minimization of sum of square error between original and the ROM is used as the fitness function as shown in Equation 23. In PSO algorithm, each single solution in search space is called as a particle. Each particle moves into the search space with an adoptable velocity and position that is dynamically varied according to the own experience and neighborhood particle experience. Each particle has a memory.

In search space, every particle has position corresponding to best fitness value. It is called as Pbest. In population, overall best fitness value of all the particles is called as Gbest [33], [34]. The position and velocity of the particle at kth iteration is used to obtain the modified velocity and position at $(\mathrm{k}+1)$ th iteration as shown in Equation (24), (25).

$$
\mathrm{J}_{\mathrm{SSE}}=\sum_{i=1}^{N} e^{2}
$$

In search space, every particle has position corresponding to best fitness value. It is called as Pbest. In population, overall best fitness value of all the particles is called as Gbest [33], [34]. The position and velocity of the particle at kth iteration is used to obtain the modified velocity and position at $(\mathrm{k}+1)$ th iteration as shown in Equation (24), (25).

$$
\begin{aligned}
& \mathrm{V}_{\mathrm{i}}{ }^{\mathrm{k}+1}=\mathrm{w}^{*} \mathrm{~V}{ }_{i}^{\mathrm{k}}+\left[\mathrm{c}_{1}{ }^{*} \text { rand }_{1}^{*}\left(\text { Pbest }_{1}{ }^{\mathrm{k}}-\mathrm{S}_{\mathrm{i}}{ }^{\mathrm{k}}\right)\right]+\left[\mathrm { c } _ { 2 } { } ^ { * } \text { rand } _ { 2 } { } ^ { * } \left(\text { Gbest }_{i}{ }^{\mathrm{k}}-\right.\right. \\
& \left.\left.\mathrm{S}_{i}^{\mathrm{k}}\right)\right] \\
& \mathrm{S}_{1}^{\mathrm{k}+1}=\mathrm{S}_{1}^{\mathrm{k}}+\mathrm{V}_{1}^{\mathrm{k}+1}
\end{aligned}
$$

Where,

$\mathrm{V}_{\mathrm{i}}^{\mathrm{k}}=$ Velocity of individuals ' $\mathrm{i}$ ' at iteration $\mathrm{k} \mathrm{w}=$ Weight parameter 
$\mathrm{c} 1, \mathrm{c} 2=$ Acceleration factors

rand 1 , rand $2=$ Random numbers between 0

and 1

$\mathrm{S}_{\mathrm{i}}{ }^{\mathrm{k}}=$ Position of individual ' $\mathrm{i}$ ' iteration $\mathrm{k}$ Pbest $_{\mathrm{i}}{ }^{\mathrm{k}}=$ Best position of individual ' $\mathrm{i}$ ' until iteration $\mathrm{k}$

Gbest $^{\mathrm{k}}=$ Best position of the group until iteration $\mathrm{k}$

The optimal ROM of all HDGT plants is identified by the above procedure using PSO. The step response of the HDGT plants with ROM is obtained and the simulation results are compared in Section V.

\section{RESULTS AND DISCUSSION}

The design of controller and analyzing the response of higher order HDGT plant in real time will be very difficult. Therefore, it is attempted to identify the ROM of all HDGT plants which mimics the characteristics of original system. Initially, the LTFM which is essential for obtaining ROM from MSM was obtained for all HDGT model by superposition principle. Then the step response of the HDGT using LTFM was obtained and compared with that of the original MSM of the respective HDGT models. The time domain specifications such as rise time (Tr), Maximum peak overshoot (Mp), settling time (Ts) and steady state error (Ess) and various performance index criteria such as Integral of Time multiplied with Absolute Error (ITAE), Integral of Absolute Error (IAE), Integral of squared Error (ISE) and Integral of Time multiplied with squared Error (ITSE) were considered for comparison [24]. On analyzing the simulation response, it was found that the LTFM of all HDGT plants are found to mimic the original characteristics as obtained from MSM.

In this paper, the ROM of all HDGT plants are obtained by using various reduction techniques as presented in section 3.2. The step response of 5001M model using its ROM by all the model order reduction techniques are obtained and compared with that of its MSM as shown in Figure 4.

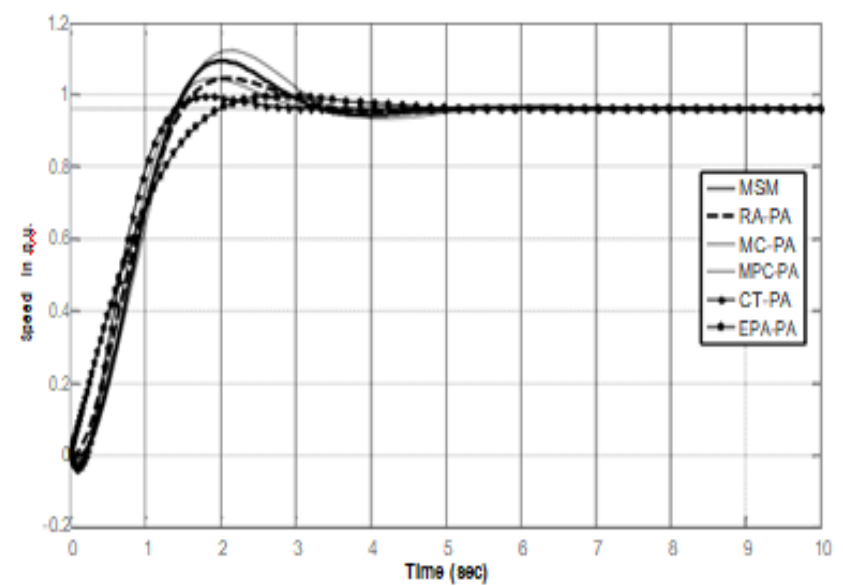

Fig 4. Response using various ROM of 5001M model
The time domain specifications and various performance index criteria are obtained and shown in Table II.

\begin{tabular}{|c|c|c|c|c|c|c|c|c|}
\hline \multirow[b]{2}{*}{ System } & \multicolumn{4}{|c|}{ Time domain specifications } & \multicolumn{4}{|c|}{ Performance indices } \\
\hline & $\begin{array}{r}\text { Mp } \\
\text { (p.u) }\end{array}$ & $\begin{array}{l}\mathbf{T r} \\
(\mathbf{S})\end{array}$ & $\begin{array}{l}\text { Ts } \\
(\mathbf{S})\end{array}$ & $\begin{array}{c}\text { Ess } \\
\text { (p.u.) }\end{array}$ & ITAE & IAE & ISE & ITSE \\
\hline MSM & 0.09 & 0.878 & 3.08 & 0.039 & 2.406 & 1.19 & 0.6433 & 0.3197 \\
\hline RA-PA & 0.04 & 0.991 & 3.15 & 0.039 & 2.26 & 1.097 & 0.5757 & 0.2772 \\
\hline $\begin{array}{c}\text { EPA- } \\
\text { PA }\end{array}$ & $\mathbf{0}$ & 1.36 & 3.75 & 0.039 & 2.157 & 1.027 & 0.4684 & 0.2395 \\
\hline $\begin{array}{c}\text { MPC- } \\
\text { PA } \\
\end{array}$ & 0.04 & 0.84 & 2.79 & 0.039 & 2.238 & 1.086 & 0.5944 & 0.2724 \\
\hline CT-PA & 0 & 0.802 & 2.26 & 0.039 & 2.178 & 1.027 & 0.5516 & 0.2403 \\
\hline MC-PA & 0.12 & 0.902 & 4.65 & 0.039 & 2.563 & 1.271 & 0.6869 & 0.3613 \\
\hline
\end{tabular}

Table 2:-Time Domain Specifications And Performance Indices Of 5001m Model

It shows that the response obtained by RA-PA technique is close to the original MSM of the HDGT plant than the other reduction techniques. Hence, RA-PA technique is identified as the best ROM among all these techniques and its reduced order transfer function is expressed in Equation (26).

$$
\mathrm{G}_{\mathrm{r}}(\mathrm{s})=\frac{-0.05454 s+3.4784}{s^{2}+2.3319 s+3.6207}
$$

For improving the response further, it is attempted to optimize the co-efficients of the above ROM using PSO algorithm as explained in Section 4.2. The PSO based reduced order transfer function model of $5001 \mathrm{M}$ is expressed in Equation (27).

$$
\mathrm{G}_{\mathrm{r}}(\mathrm{s})=\frac{-0.05454 s+3.0333}{s^{2}+1.8953 s+3.1570}
$$

Then the step responses are obtained and compared with that of MSM and RA-PA technique as shown in Figure 5. The respective time domain specifications and performance index criteria are obtained and furnished in Table III. 


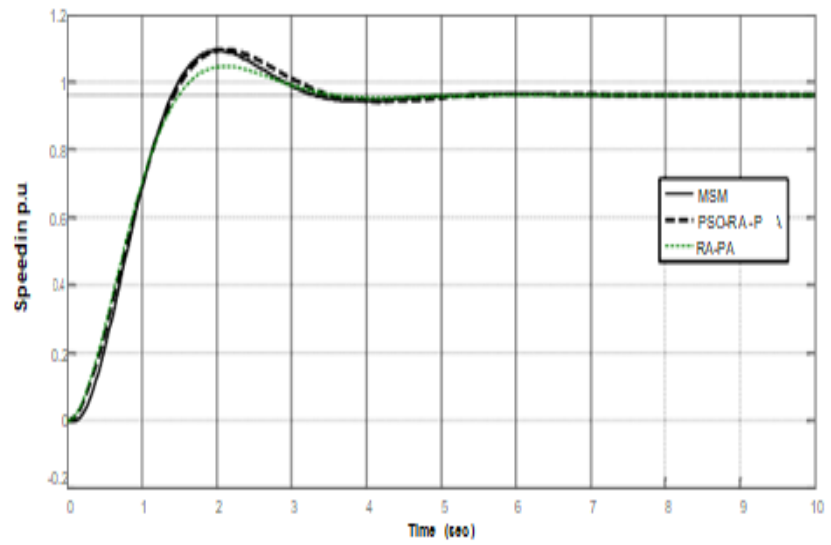

Fig 5:- Response of optimal ROM of 5001M model

\begin{tabular}{|c|c|c|c|c|c|c|c|c|}
\hline \multirow{2}{*}{ System } & \multicolumn{4}{|c|}{ Time domain specifications } & \multicolumn{4}{c|}{ Performance indices } \\
\cline { 2 - 8 } & $\begin{array}{c}\text { Mp } \\
\text { (p.u) }\end{array}$ & $\begin{array}{c}\text { Tr } \\
\text { (S) }\end{array}$ & $\begin{array}{c}\text { Ts } \\
(\text { S) }\end{array}$ & $\begin{array}{c}\text { Ess } \\
\text { (p.u.) }\end{array}$ & $\begin{array}{c}\text { ITA } \\
\text { E }\end{array}$ & IAE & ISE & ITSE \\
\hline MSM & 0.09 & 0.878 & 3.08 & 0.039 & 2.406 & 1.19 & 0.6433 & 0.3197 \\
\hline $\begin{array}{c}\text { PSO-RA- } \\
\text { PA }\end{array}$ & 0.09 & 0.851 & 3.28 & 0.039 & 2.413 & 1.167 & 0.6003 & 0.3028 \\
\hline RA-PA & 0.04 & 0.991 & 3.15 & 0.039 & 2.26 & 1.097 & 0.5757 & 0.2772 \\
\hline
\end{tabular}

Table 3:- Time Domain Specifications And Performance Indices Of Optimal Rom 5001m Model

The simulation results show that the PSO based ROM yields better transient and steady state response. Therefore, the PSO tuned RA-PA technique (PSO- RA - PA) based ROM is identified as an optimal ROM for 5001M HDGT model.

The ROM of all HDGT models are identified by the same procedure and the responses are found to be similar. Therefore, the simulation response of 7001Ea and 9001Ea are alone presented in this paper. The step response of $7001 \mathrm{Ea}$ and 9001Ea models using various model order reduction techniques are obtained and compared with that of MSM as shown in Figure 6 and 7.

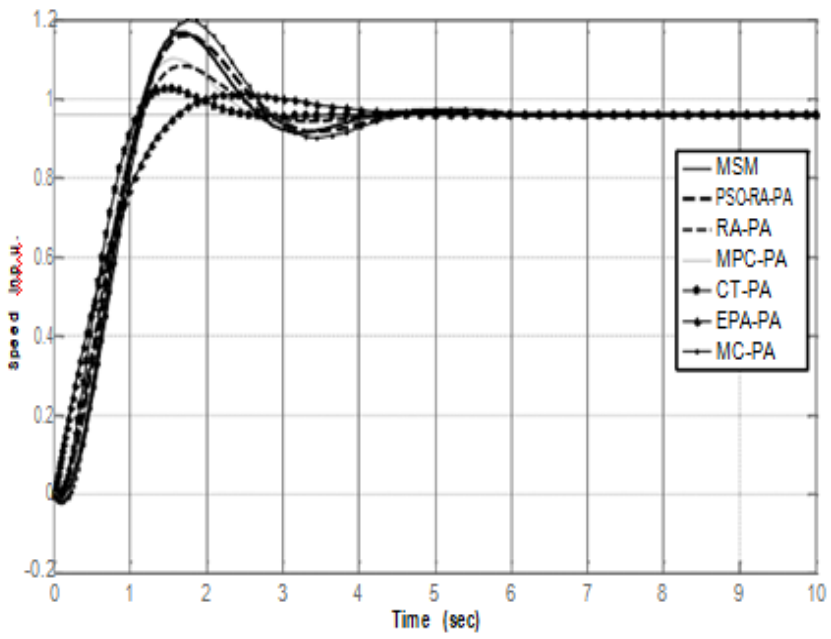

Fig 6:- Response of optimal ROM of 7001Ea model

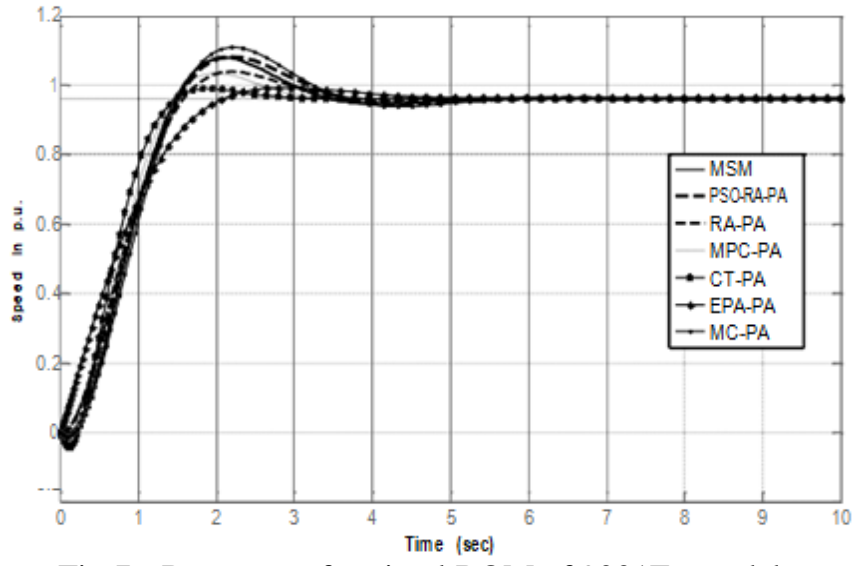

Fig 7:- Response of optimal ROM of 9001Ea model

The time domain specifications and performance indices of 7001Ea and 9001Ea HDGT plants by the above techniques are obtained and presented in Table IV and $\mathrm{V}$ respectively.

\begin{tabular}{|c|c|c|c|c|c|c|c|c|}
\hline \multirow{2}{*}{ System } & \multicolumn{7}{|c|}{ Time domain specifications } & \multicolumn{5}{c|}{ Performance indices } \\
\cline { 2 - 9 } & $\begin{array}{c}\mathrm{M}_{\mathrm{p}} \\
(\mathrm{p} . \mathrm{u})\end{array}$ & $\begin{array}{c}\mathrm{T}_{\mathrm{r}} \\
(\mathrm{S})\end{array}$ & $\begin{array}{c}\mathrm{T}_{\mathrm{s}} \\
(\mathrm{S})\end{array}$ & $\begin{array}{c}\mathrm{E}_{\text {ss }} \\
\text { (p.u.) }\end{array}$ & ITAE & IAE & ISE & ITSE \\
\hline MSM & 0.17 & 0.686 & 3.85 & 0.039 & 2.45 & 1.152 & 0.571 & 0.284 \\
\hline PSO-RA-PA & 0.16 & 0.752 & 4.1 & 0.039 & 2.45 & 1.119 & 0.5219 & 0.2657 \\
\hline RA-PA & 0.08 & 0.773 & 2.61 & 0.039 & 2.233 & 1.022 & 0.4813 & 0.2185 \\
\hline EPA-PA & 0.01 & 1.13 & 3.68 & 0.039 & 2.025 & 0.9264 & 0.501 & 0.1932 \\
\hline MPC-PA & 0.02 & 0.722 & 2.17 & 0.039 & 2.25 & 1.022 & 0.5075 & 0.2257 \\
\hline CT-PA & 0.03 & 0.689 & 2.14 & 0.039 & 2.098 & 0.8986 & 0.4338 & 0.1832 \\
\hline MC-PA & 0.2 & 0.706 & 4.19 & 0.039 & 2.594 & 1.235 & 0.6182 & 0.3301 \\
\hline
\end{tabular}

Table 4:- Time Domain Specifications And Performance Indices Of 7001ea Model

\begin{tabular}{|c|c|c|c|c|c|c|c|c|}
\hline \multirow{2}{*}{ System } & \multicolumn{5}{|c|}{ Time domain specifications } & \multicolumn{5}{c|}{ Performance indices } \\
\cline { 2 - 9 } & $\begin{array}{c}\mathbf{M}_{\mathrm{p}} \\
\text { (p.u) }\end{array}$ & $\begin{array}{c}T_{\mathrm{r}} \\
(\mathrm{S}\end{array}$ & $\begin{array}{c}\mathrm{T}_{\mathrm{s}} \\
(\mathrm{S})\end{array}$ & $\begin{array}{c}\mathbf{E}_{\text {ss }} \\
\text { (p.u. }\end{array}$ & ITAE & IAE & ISE & ITSE \\
\hline MSM & 0.08 & 0.923 & 3.18 & 0.039 & 2.395 & 1.199 & 0.6591 & 0.3299 \\
\hline PSO-RA-PA & 0.08 & 1.01 & 3.39 & 0.039 & 2.43 & 1.185 & 0.6196 & 0.3167 \\
\hline RA-PA & 0.04 & 1.04 & 3.26 & 0.039 & 2.428 & 1.184 & 0.6195 & 0.3164 \\
\hline EPA-PA & 0 & 1.4 & 3.76 & 0.039 & 2.216 & 1.065 & 0.4917 & 0.2571 \\
\hline MPC-PA & 0.03 & 0.88 & 2.86 & 0.039 & 2.259 & 1.107 & 0.6153 & 0.2871 \\
\hline CT-PA & 0 & 0.828 & 2.25 & 0.039 & 2.226 & 1.065 & 0.5805 & 0.2512 \\
\hline MC-PA & 0.11 & 0.947 & 4.66 & 0.039 & 2.57 & 1.284 & 0.7038 & 0.373 \\
\hline
\end{tabular}

Table 5:- Time Domain Specifications And Performance Indices Of 9001ea Model 
On analyzing the step responses, time domain specifications and performance index criteria of the HDGT plants and it is found that the PSO-RA-PA based ROM yields better transient and steady state responses than the other reduction techniques. Based on the simulation responses and comparative results, the PSO based RA-PA is identified as the optimal ROM for all HDGT plants in grid connected operation.

\section{CONCLUSION}

An attempt has been made in this paper to obtain the ROM for all HDGT plants in order to reduce the complexity of controller development in real time environment. Various model order reduction techniques such as EPA, RA, CT, MPC, MC, PA etc. are used for model order reduction of HDGT plants. The step responses are obtained and compared based on the time domain specifications and various performance index criteria. It shows that the response obtained using RA-PA based ROM is found to be better for all HDGT plants. Further, the co-efficients of RA$\mathrm{PA}$ reduced order model are optimized using PSO in order to improve the response. The simulation results of all HDGT plants are obtained using the optimized reduced order models are compared with that of the original higher order system. It reveals that the PSO-RA-PA technique based ROM yield better transient as well as steady state response than any other technique and hence identified as the optimal ROM for all HDGT plants. The optimal reduced order model can further be used to develop the controllers and analyze the response of HDGT plants in grid connected operation.

\section{REFERENCES}

[1]. Ministry of New and Renewable Energy, Government of India. Available online at: http://www.mnre.gov.in

[2]. Jittarat Satonsaowapak, Thanatchai. Kulworawanichpong, Ratchadaporn Oonsivilai and Anant Oonsivilai, "Gasifier System Identification for Biomass Power Plants using Neural Network", World Academy of Science, Engineering and Technology, vol.5, No.12, pp.134-139, 2011.

[3]. Mohammad Reza Bank Tavakoli , Behrooz Vahidi and Wolfgang Gawlik, "An Educational guide to extract the parameters of heavy duty gas turbines model in dynamic studies based on operational data", IEEE transactions on power systems, vol.24, no.3, pp.13661374, 2009.

[4]. W.I. Rowen, "Simplified Mathematical representation of heavy duty gas turbines", ASME Journal of Engineering for Power, Vol.105, No.4, pp.865-869, 1983.

[5]. L.M. Hajagos and G.R. Berube, "Utility Experience with Gas turbine testing and Modeling", IEEE power Engineering Society Winter Meeting, Vol.2, pp.671677, 2001.

[6]. L. N. Hannett and Afzal Khan, "Combustion Turbine Dynamic Model Validation from Tests", IEEE Transactions on Power Systems, Vol.8, No.1, pp.152$158,1993$.
[7]. J. H. Kim, T.W. Song, T.S. Kim and S.T. Ro, "Model Development and Simulation of Transient Behaviour of Heavy Duty Gas Turbines", Transactions of the ASME. Journal of Engineering for Gas Turbines and Power, vol.123, pp.589-594, 2001.

[8]. Pouyan Pourbeik and Fhedzisani Modau, "Model Development and Field Testing of a Heavy Duty Gas Turbine Generator", IEEE transactions on power systems, vol.23, no. 2, pp.664-672, 2008.

[9]. S. Balamurugan, R. Joseph Xavier and A. Ebenezer Jeyakumar, "Simulation of response of gas turbine plant with controllers", Proceedings of National System Conference, Ref No.P105, Manipal, 2007.

[10]. S. Balamurugan, R. Joseph Xavier and Ebinezer Jeyakumar, "Selection of governor and optimization of its droop setting and rotor time constant for heavy duty gas turbine plants", Indian Journal of Power and River Valley Development,Vol.57, pp.35-37, 2007.

[11]. John Mantzaris and Costas Vournas, "Modelling and Stability of a Single-Shaft Combined Cycle Power Plant", International journal of Thermodynamics, vol.10, no.2, pp.71-78, 2007.

[12]. H.E.M.A. Shalan, M.A. Moustafa Hassan and A.B.G. Bahgat, "Comparative Study on Modelling Of Gas Turbines in Combined Cycle Power Plants", International Middle East Power Systems Conference, paper ID.317, pp.970-976, 2010.

[13]. Naoto Kakimoto and Kazuhiro Baba, "Performance of Gas Turbine- Based Plants During Frequency Drops", IEEE transactions on power systems, vol.18, no.3, pp.1110-1115, 2003.

[14]. Hadi Ghorbani, Ali Ghaffari and Mehdi Rahnama, "Constrained Model Predictive Control Implementation for a Heavy-Duty Gas Turbine Power Plant", WSEAS transactions on systems and control, vol.3, Issue.6, pp.507-516, 2008.

[15]. M. Mohamed Iqbal, R. Joseph Xavier, D. Arun Kumar, G. RajKumar, P. Selva Kumar and C. Tamilarasan, "A sample survey on biomass gasifier power plants", International Conference on Emerging Technologies in Renewable Energy, Ref. No. P-87, Chennai, 2010.

[16]. M. Mohamed Iqbal and R. Joseph Xavier, "Factors influencing the operation of the Biomass gasifier power plants", Proceedings of Second World Renewable Energy Technology Congress and Expo2011, New Delhi, 2011.

[17]. M. Mohamed Iqbal and R. Joseph Xavier, "A review of controllers for isolated and grid connected operation of biomass power plants", International Conference on Renewable Energy Technologies (ICORET-2011), pp. 366-371, Coimbatore, India, 2011.

[18]. S. Balamurugan and R. Joseph Xavier, "Modelling of biomass power plant having low rotor time constant for stability studies", National conference on power engineering practices and energy management, pp.165-167, 2005.

[19]. S. Balamurugan, R. Joseph Xavier and A. Ebinezer Jeyakumar, "ANN Controller for Heavy Duty Gas Turbine Plant”, vol.3, no.12, pp.1765- 1771, 2008. 
[20]. S. Balamurugan, R. Joseph Xavier and A. Ebinezer Jeyakumar, "Control of Heavy Duty Gas Turbine Plants for Parallel Operation Using Soft Computing Techniques", Electric Power Components and Systems,vol.37, pp.1275-1287, 2009.

[21]. S. Selvakumar, S. Balamurugan and R. Joseph Xavier, "Development of Controller for Parallel Operation of Gas Turbine Plants", Electric Power Components and Systems, vol. 41, no. 1, pp.100-109,2012.

[22]. Mustafa Mohamed Iqbal and Rayappan Joseph Xavier, "Fuzzy Self tuning PID Controller for Speedtronic Governor Controlled Heavy Duty Gas Turbine Plants", Electric Power Components and Systems, vol.42, no. 14, 2014.

[23]. S. Panda, J.S. Yadav, N.P. Patidar and S. Ardil, "Evolutionary Techniques for Model Order reduction of large scale Linear Systems", International Journal of Electrical, Robotics, Electronics and Communications Engineering, vol.6, no.9, pp.115-121, 2012.

[24]. Mohamed Iqbal, R. Joseph Xavier and Ananthi. P, "Linearized Transfer Function Model of Biomass Based Heavy Duty Gas Turbine Plants", International Journal of Applied Engineering Research, Vol.10, No.10, pp.9637-9642, 2015.

[25]. Sofiane Khadraoui, Hazem Nounou, Mohamed Nounou, Aniruddha Datta and Shankar P. Bhattacharyya (2014), 'A model-free design of reduced-order controllers and application to a DC servomotor', Automatica, Vol.50, No.8, pp.2142-2149.

[26]. Jay Singh, Kalyan Chatterjee, C. B. Vishwakarma (2014), 'System Reduction by Eigen Permutation Algorithm and Improved Pade Approximations', International Journal of Mathematical, Computational, Physical and Quantum Engineering, Vol.8 No.1.

[27]. D. Kranthi Kumar, S. K. Nagar and J. P. Tiwari(2011), 'Model Order Reduction of Interval Systems Using Routh Approximation and Cauer Second Form', International Journal of Advances in Science and Technology, Vol. 3, No.2.

[28]. S. K. Agrawal, D. Chandra and I. A. Khan, 'Order Reduction of Linear System Using Clustering, Integral Square Minimization and Dominant Pole Technique', International Journal of Engineering and Technology, Vol.3, No.1, pp. 64-67, 2011

[29]. C.B. Vishwakarma, 'Order Reduction using Modified Pole Clustering and Pade Approximations', International science index, Vol.5, No.8, pp.697-701, 2011.

[30]. D. Kranthi kumar, Dr. S. K. Nagar and Dr. J. P. Tiwari, 'Model Order Reduction of Interval Systems Using Mihailov Criterion and Routh Approximation', International Journal of Engineering Science and Technology, Vol. 3, No. 7, pp. 5593-5598, July 2011

[31]. Parvendra Kumar and Rajendra Prasad (2012), 'Controller Design using Pade approximation and mixed methods', International journal Computer Technology and Applications,Vol.3, No.4, pp.15041509.
[32]. J. Kennedy and Eberhart RC, 'Particle Swarm Optimization', Proc. IEEE Int. Conf. Neur. Netw. IEEE Service Centre, Piscataway, NJ. 4:1942-1948, 1995.

[33]. Amit Konar, Deepyaman Maiti and Sagnik Biswas (2008), 'Design of a Fractional Order PID Controller Using Particle Swarm Optimization Technique', Second National Conference on Recent Trends in Information Systems.

[34]. Gomathi P. And Manigandan T. (2013), 'Particle swarm optimisation based proportional integral and derivative (PID) controller design for linear discrete time system using reduced order model', Academic Journals, Vol.8, No.25, pp. 1171-1179. 